\title{
Pipeline in clinical practice in 2011
}

\author{
David Fiorella
}

Received: 29 August 2011 / Accepted: 5 September 2011 /Published online: 29 September 2011

(C) Springer-Verlag 2011

Henkes and his team present a "real world" series of over 100 aneurysms and intracranial dissections treated with the Pipeline embolization device (PED). These data provide important insight into the present status of the clinical application of the Pipeline device and in particular the challenges we face within the context of this emerging science of parent artery reconstruction with flow diverters.

The Henkes series differs, to some extent, from the prior studies of Pipeline (e.g., PUFS, PITA, the Buenos Aires Experience) in that most of the aneurysms in the present series are small ( 49 of 63 treated saccular aneurysms measured less than $5 \mathrm{~mm}$; average size $3.8 \mathrm{~mm}$ ); a significant percentage $(30 \%)$ had been previously treated with stents, and a significant number involved the posterior circulation $[1,2]$.

To some extent, these differences represent the gradual transition of this technology from a novel, investigational approach reserved for otherwise untreatable lesions to a more established alternative to predicate techniques that is being integrated into a high-volume cerebrovascular practice. In fact, over the 15-month time course of this series, the investigators indicate that about one-third of all aneurysms treated with endovascular techniques at their institution were treated with Pipeline. One would imagine that if the denominator were limited to unruptured aneurysms that the proportion would be considerably higher.

In agreement with previous studies, this technically proficient and highly experienced group of operators reported a very high rate of technical success $(99 \%)$ with respect to deploying the devices to achieve a successful reconstruction

\section{Fiorella $(\bowtie)$}

Department of Neurological Surgery, Health Sciences Center T-12

080, Stony Brook University Medical Center,

Stony Brook, NY 11794-8122, USA

e-mail: dfiorella@notes.cc.sunysb.edu of the parent artery. The efficacy of the flow diversion strategy was slightly lower than that reported in other series with observed rates of complete occlusion at 3 months and 10 months of 52 and $74 \%$ respectively [1-3]. This may in part be related to the high proportion of fusiform and posterior circulation aneurysms included in the present series.

As previously reported, the observed rate of in-construct stenosis (ICS) was low with no observed cases of high grade $(>50 \%)$ or symptomatic ICS in the present series.

It had been suggested previously that treatment with conventional stent-supported coiling might impair the efficacy of subsequent re-treatment with Pipeline [1,2]. The present data, which represent the largest experience to date with respect to this scenario, do not reflect this. The authors reported complete occlusion rates of $69 \%$ and $65 \%$ for lesions with and without pre-existing in situ conventional, self-expanding intracranial stents, respectively. Although the presence of pre-existing stents did not seem to impair the efficacy of flow diversion in regard to achieving complete lesion occlusion, there was a trend toward higher rates of peri-procedural complications when these devices were in place at the time of the procedure- $2 \%$ in patients without preexisting conventional stents and $13 \%$ in patients with them.

The delayed peri-procedural complications encountered during the series reflect the key issues which have become manifest during the initial clinical application of the Pipeline device in practice.

1. Delayed ipsilateral parenchymal hemorrhage (occurring hours to days after an initially successful procedure) was observed in 3 of 88 patients in the current series (3.4\%). While technically an "uncommon" occurrence, the frequency of these events clearly outstrips that which would be expected for spontaneous hemorrhage related solely to dual anti-platelet medications. The rate, 
as the authors point out, also seems to exceed that which has been reported in association with conventional stentassisted coiling [4]. The finding that these hemorrhages are all within the vascular distribution of the treated artery seems to link these events to the Pipeline procedure. While the mechanism of these events is still not understood, it seems logical that they could be related to hemorrhage into pre-existing, silent, ischemic lesions incurred during the procedure. Because this is a lowfrequency event occurring in the relatively small population of patients with intracranial aneurysms treated with flow diverters, it will be extremely challenging to accurately quantify and understand these events going forward. The present series provides significant value added in regard to starting to define the frequency of delayed IPH after flow diversion.

2. Delayed rupture of a previously unruptured aneurysm was observed in a single patient on post-operative day 3. Importantly this patient was treated with coil embolization in addition to flow diversion with PED, demonstrating that endosaccular occlusion of the aneurysm does not necessarily provide absolute protection against delayed rupture.

In conclusion, the authors provide supportive evidence that the Pipeline can be successfully applied to achieve the treatment of aneurysms that would be difficult to address with conventional endovascular or surgical techniques as well as aneurysms that have failed prior attempts at treatment. The authors provide important early insight into some of the challenges that are emerging as the Pipeline device is integrated into clinical practice.

Conflict of interest DF consults (Pipeline proctor) for ev3 Codmanand Nfocus. He receives institutional research grant funding and is an unpaid consultant for Microvention, salary support related to SAMMPRIS from the NIH, and institutional research grant funding from Siemens Medical Imaging.

\section{References}

1. Nelson PK, Lylyk P, Szikora I, Wetzel SG, Wanke I, Fiorella D (2011) The pipeline embolization device for the intracranial treatment of aneurysms trial. AJNR Am J Neuroradiol 32 (1):34-40

2. Lylyk P, Miranda C, Ceratto R et al (2009) Curative endovascular reconstruction of cerebral aneurysms with the pipeline embolization device: the Buenos Aires experience. Neurosurgery 64(4):632-642, discussion 642-633; quiz N636

3. Szikora I, Berentei Z, Kulcsar Z et al (2010) Treatment of intracranial aneurysms by functional reconstruction of the parent artery: the budapest experience with the pipeline embolization device. AJNR Am J Neuroradiol 31(6):1139-1147

4. Kim DJ, Suh SH, Kim BM, Kim DI, Huh SK, Lee JW (2010) Hemorrhagic complications related to the stent-remodeled coil embolization of intracranial aneurysms. Neurosurgery 67(1):73-78, discussion $78-79$ 